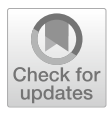

Cite as

Nano-Micro Lett.

(2021) 13:27

Received: 25 August 2020

Accepted: 15 October 2020

Published online: 20 November 2020

(C) The Author(s) 2020

\section{A Nano-Micro Engineering Nanofiber for Electromagnetic Absorber, Green Shielding and Sensor}

\author{
Min Zhang ${ }^{1}$, Chen Han $^{1}$, Wen-Qiang Cao ${ }^{1}$, Mao-Sheng Cao ${ }^{1}{ }^{凶}$, Hui-Jing Yang ${ }^{2}$, \\ Jie Yuan $^{3 凶}$
}

\title{
HIGHLIGHTS
}

- The role of electron transport characteristics in electromagnetic (EM) attenuation can be generalized to other EM functional materials.

- The integrated functions of efficient EM absorption and green shielding open the view of EM multifunctional materials.

- A novel sensing mechanism based on intrinsic EM attenuation performance and EM resonance coupling effect is revealed.

\begin{abstract}
It is extremely unattainable for a material to simultaneously obtain efficient electromagnetic (EM) absorption and green shielding performance, which has not been reported due to the competition between conduction loss and reflection. Herein, by tailoring the internal structure through nano-micro engineering, a $\mathrm{NiCo}_{2} \mathrm{O}_{4}$ nanofiber with integrated EM absorbing and green shielding as well as strain sensing functions is obtained. With the improvement of charge transport capability of the nanofiber, the performance can be converted from EM absorption to shielding, or even coexist. Particularly, as the conductivity rising, the reflection loss declines from -52.72 to $-10.5 \mathrm{~dB}$, while the EM interference shielding effectiveness increases to $13.4 \mathrm{~dB}$, suggesting the coexistence of the two EM functions. Furthermore, based on the high EM absorption,

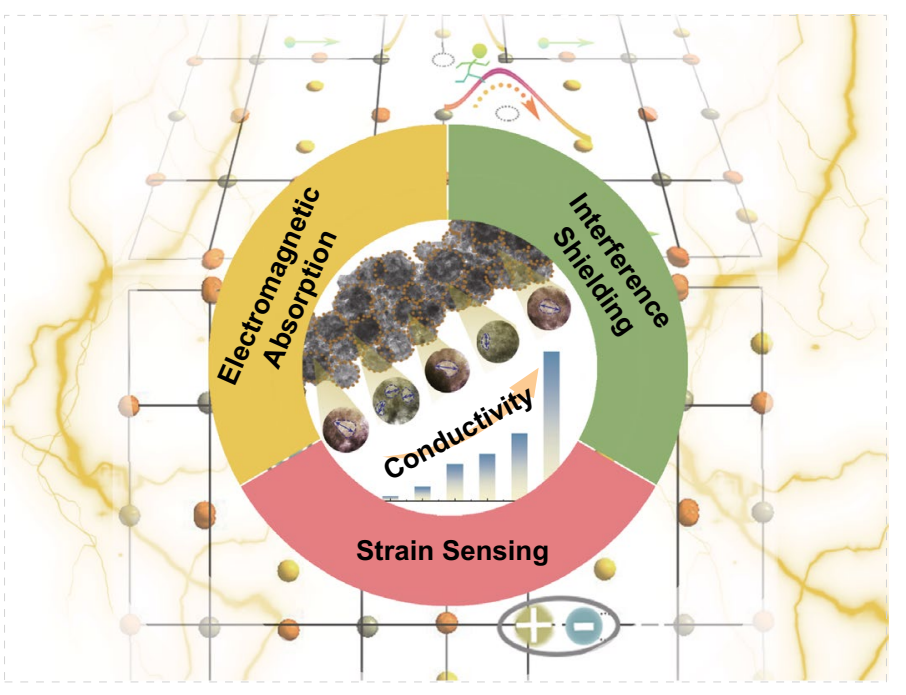
a strain sensor is designed through the resonance coupling of the patterned $\mathrm{NiCo}_{2} \mathrm{O}_{4}$ structure. These strategies for tuning EM performance and constructing devices can be extended to other EM functional materials to promote the development of electromagnetic driven devices.
\end{abstract}

KEYWORDS Electromagnetic absorber; Electromagnetic shielding; $\mathrm{NiCo}_{2} \mathrm{O}_{4}$ nanofiber; Sensor

Min Zhang and Chen Han contributed equally to this work.

$\checkmark$ Mao-Sheng Cao, caomaosheng@ bit.edu.cn; Hui-Jing Yang, yanghuijing619@126.com; Jie Yuan, yuanjie4000@ sina.com

1 School of Materials Science and Engineering, Beijing Institute of Technology, Beijing 100081, People's Republic of China

2 Department of Physics, Tangshan Normal University, Tangshan 063000, People's Republic of China

3 School of Information Engineering, Minzu University of China, Beijing 100081, People's Republic of China 


\section{Introduction}

Porous nanostructures, with great potential for supercapacitors, electromagnetic (EM) attenuation, catalysis, and biological medicine, are attracting growing interest [1-11]. A thorough comprehension of the growth mechanism significantly facilitates the tailoring of porous morphology and analysis of material properties. Especially for EM properties, the superiority of porous nanostructures including lightweight, high specific surface, and rich electron transmission channels exposes the significance in promoting the innovation of EM functional materials.

EM functional materials have always been a hot spot in the information explosion era, and their applications in ultra-long-distance energy transmission, military stealth camouflage, and anti-interference of electrical equipment cannot be ignored [12-19]. Generally, the EM absorption mechanism fatefully depends on the impedance matching level, and incident EM wave is attenuated by dielectric or/ and magnetic losses [20-28]. Many meritorious electromagnetic absorbing materials are emerging in recent decades, such as carbon materials, metal-based material, and polymers. [29-32]. Chen's group conducted a series of studies to explore microwave absorbing materials [33-38]. Particularly, polyaniline and polypyrrole exhibit strong microwave absorption, while polyoxometalates and organic metal halide feature multi-band microwave absorption.

Compared with EM absorbing materials, the performance of shielding materials is contributed not only by effective absorption but by reflection [39-43]. The robust reflection caused by remarkable electrical property enables them to be integrated into contact lenses and clothing to protect life from EM radiation $[44,45]$. However, the strong secondary reflection adds extra insecurity to the environment. Thus, "green" shielding materials emerge by tailoring the nanostructure to raise effective absorption but reflection [46]. It is unattainable for the EM absorption material to have the EM interference (EMI) shielding performance concurrently due to the feature that reflection and absorption are opposites, and conductivity $(\sigma)$ simultaneously dominates conduction loss $\left(\varepsilon_{\mathrm{c}}{ }^{\prime \prime}\right)$ and reflection. That is, there is a competition effect between conduction loss and reflection, and the balance between $\varepsilon_{\mathrm{c}}{ }^{\prime \prime}$ and reflection is hard to obtain.

Integrating EM property with electronic devices is an inevitable trend for innovation and breakthroughs in advanced electromagnetic devices [47]. However, such research associated with the EM multifunctional material or device is very limited, although EM functional materials are in a booming stage. The single function mode hardly captures the rapid development of EM devices.

Herein, a new dual-template nano-micro engineering is presented to tailor the internal structure of porous $\mathrm{NiCo}_{2} \mathrm{O}_{4}$ nanofiber. With customizing the template state, the polarization and charge transport properties are modulated. By analyzing the balance of $\varepsilon_{\mathrm{c}}$ " and reflected EM wave, the shielding function is turned on by the "switch" of $\sigma$. Thus, EM absorbing and shielding can be achieved simultaneously. The mechanism of the state transition from EM absorption to shielding is gotten insight into. A patterned strain induction device, integrating the intrinsic EM absorption performance and resonance coupling effect of patterned structure, is designed. This sensor enables wireless and real-time detection of strain, potentially used in monitoring the state of large devices in harsh environments.

\section{Experimental Section}

\subsection{Synthesis of $\mathrm{NiCo}_{2} \mathrm{O}_{4}$}

The precursor was synthesized by electrospinning method. In particular, polyacrylonitrile $(500 \mathrm{mg})$ and DMF $(10 \mathrm{~mL})$ were stirred for $12 \mathrm{~h}$ at $55{ }^{\circ} \mathrm{C} .560 \mathrm{mg}$ of $\mathrm{Co}(\mathrm{Ac})_{2} \cdot 4 \mathrm{H}_{2} \mathrm{O}$ and $240 \mathrm{mg}$ of $\mathrm{Ni}(\mathrm{Ac})_{2} \cdot 4 \mathrm{H}_{2} \mathrm{O}$ were added to the mixture with stirring for $6 \mathrm{~h}$. Then, the solution was injected into the syringe to start electrospinning. The feeding speed was set to $0.1 \mathrm{~mm} \mathrm{~min}^{-1}$, and the voltage was set to $16 \mathrm{kV}$. The as-spun precursor was achieved after dried for $12 \mathrm{~h}$ at $60{ }^{\circ} \mathrm{C}$. The Ni-Co@C was synthesized by a two-step calcination method. Firstly, the precursor was heat treated at $180{ }^{\circ} \mathrm{C}$ for $2 \mathrm{~h}$ in $\mathrm{N}_{2}$. Then, it was heat treated at 500,600, and $700{ }^{\circ} \mathrm{C}$, respectively, for $2 \mathrm{~h}$ in $\mathrm{N}_{2}$. The Ni-Co@ $\mathrm{C}$ nanofiber was obtained. Finally, porous $\mathrm{NiCo}_{2} \mathrm{O}_{4}$ nanofiber was heat treated at $400{ }^{\circ} \mathrm{C}$ in air.

\subsection{Fabrication of $\mathrm{NiCo}_{2} \mathrm{O}_{4}$ Composites}

$\mathrm{NiCo}_{2} \mathrm{O}_{4}$ powders with different loading content $(50,70$, and $90 \mathrm{wt} \%$ ) were mixed with paraffin wax. Modest doses of $\mathrm{C}_{4} \mathrm{H}_{10} \mathrm{O}$ were added to the $\mathrm{NiCo}_{2} \mathrm{O}_{4}$-paraffin mixture with ultrasound until a uniform powder was obtained. Then, it 
was pressed into a toroidal EM mold. The inner diameter of the toroidal composite is $3.00 \mathrm{~mm}$, and the outer diameter is $7.00 \mathrm{~mm}$.

\subsection{Characterization}

The morphology and microstructure of Ni-Co@C and $\mathrm{NiCo}_{2} \mathrm{O}_{4}$ were observed by scanning electron microscopy (SEM; HITACHI S-4800) and transmission electron microscopy (TEM; JEOL-2100). The crystal structure, elements, and composition were analyzed by an X-ray diffractometer (XRD; X'Pert PRO), X-ray photoelectron spectrometer (XPS; PHI Quanteral II (Japan)), Raman spectrometer (Renishaw Raman RE01), and Mettler Toledo thermal analysis TGA/DSC system.

\subsection{Calculation of Dielectric Properties}

$\varepsilon_{\mathrm{p}}{ }^{\prime \prime}$ and $\varepsilon_{\mathrm{c}}{ }^{\prime \prime}$ are the dielectric loss contributed by polarization relaxation and charge transport, respectively, which can be obtained according to Debye theory (Eqs. 1-3):

$\varepsilon^{\prime \prime}=\frac{\varepsilon_{s}-\varepsilon_{\infty}}{1+(2 \pi f)^{2} \tau^{2}} \omega \tau+\frac{\sigma}{2 \pi f \varepsilon_{0}}=\varepsilon_{p}^{\prime \prime}+\varepsilon_{c}^{\prime \prime}$

$\varepsilon_{p}^{\prime \prime}=\frac{\varepsilon_{s}-\varepsilon_{\infty}}{1+(2 \pi f)^{2} \tau^{2}} \omega \tau=\varepsilon^{\prime \prime}-\varepsilon_{c}^{\prime \prime}$

$\varepsilon_{c}^{\prime \prime}=\frac{\sigma}{2 \pi f \varepsilon_{0}}$

where $\varepsilon_{\mathrm{s}}$ is the relative permittivity at static, and $\varepsilon_{\infty}$ is that at "infinite" high frequency. $\tau$ is the relaxation time. $f$ is the frequency. $\sigma$ is the DC conductivity, and $\varepsilon_{0}$ is the vacuum permittivity.

\subsection{Calculation of Reflection Loss}

The input impedance is calculated by Eq. 4 :

$Z_{\text {in }}=\sqrt{\frac{\mu_{r}}{\varepsilon_{r}}} \tanh \left[j \frac{2 \pi}{c} \sqrt{\varepsilon_{r} \mu_{r}} f d\right]$

where $c$ is the light velocity and $d$ is the thickness of the sample. The reflection loss (RL) is calculated by Eq. 5:
$\mathrm{RL}(\mathrm{dB})=20 \lg \frac{\left|Z_{\text {in }}-1\right|}{\left|Z_{\text {in }}+1\right|}$

\subsection{Calculation of Electromagnetic Interference Shielding Performance}

EMI shielding effectiveness ( $\mathrm{SE}$ ), $\mathrm{SE}_{\mathrm{A}}$, and $\mathrm{SE}_{\mathrm{R}}$ can be calculated by Eqs. 6-8,

$\mathrm{SE}(\mathrm{dB})=10 \times \lg (1 / T)$

$\mathrm{SE}_{R}(\mathrm{~dB})=10 \times \lg (1 /(1-R))$

$\mathrm{SE}_{A}(\mathrm{~dB})=10 \times \lg ((1-R) / T)$

\subsection{Calculation of $\boldsymbol{A}_{\text {eff }}$}

The effective absorption efficiency $A_{\text {eff }}$ is calculated by Eq. 9:

$A_{\text {eff }}=\frac{1-R-T}{1-R}$

where $R$ and $T$ are the reflection and transmission coefficient.

\section{Results and Discussion}

\subsection{Structure Characterization}

The growth process and compositional evolution of $\mathrm{NiCo}_{2} \mathrm{O}_{4}$ are shown in Fig. 1a. Precursor nanofibers composed of polyacrylonitrile (PAN) and metal ions $\left(\mathrm{Ni}^{2+}: \mathrm{Co}^{2+}=1: 2\right)$ are prepared by electrospinning strategy (Fig. 1b). After calcined for $4 \mathrm{~h}$ in $\mathrm{N}_{2}$, PAN nanofiber is carbonized with removal of non-carbon elements and $\mathrm{Ni}^{2+} / \mathrm{Co}^{2+}$ ions are reduced to $\mathrm{Ni} / \mathrm{Co}$, giving rise to the formation of $\mathrm{Ni}-\mathrm{Co} @ \mathrm{C}$ nanofiber (Fig. 1c) $[48,49]$. Then, the oxidation is proceeded by heating Ni-Co@ $\mathrm{C}$ at $400{ }^{\circ} \mathrm{C}$ in air (Fig. 1a). C fiber is used as a template to support the oxidation and assembly of bimetallic particles. The SEM images in Fig. 1d, e show the in situ assembly process of oxide nanoparticles into a fibrous structure. Ni-Co particles on the nanofiber surface are oxidized first. Then, $\mathrm{C}$ fiber is gradually burned with the metal particles inside being exposed and oxidized continuously until the reaction is complete. 
When obtaining Ni-Co@C, calcination temperature can effectively tailor the $\mathrm{C}$ template size. In Fig. 2a, by raising the temperature, the purification of carbonized PAN continues, and the carbon consumption in reducing metal ions increases as the reaction progress more completely, resulting in thinner $\mathrm{C}$ nanofiber [48]. The corresponding morphology is revealed in Fig. 2b. The density of Ni-Co nanoparticles denoted by the bright white dots increases with the raised temperature, indicating that the thinner $\mathrm{C}$ fibers expose more metallic particles. The TEM images in Fig. 2f, g confirm that $\mathrm{Ni}-\mathrm{Co}$ particles denoted by the dark spots are implanted on and inside the $\mathrm{C}$ fibers randomly, with the interplanar spacing of $0.204 \mathrm{~nm}$, in accordance with the (111) planes of face-centered cubic. This suggests that Ni replaces part of cobalt atoms to form $\mathrm{Fm}-3 \mathrm{~m} \mathrm{NiCo}_{2}$ alloy [50]. The final oxidation products corresponding to 500,600 , and $700{ }^{\circ} \mathrm{C}$ are denoted by $\mathrm{N} 1, \mathrm{~N} 2$, and $\mathrm{N} 3$, respectively.

During the assembly of bimetallic oxide nanoparticles, there are two categories of the oxidation morphologies (Fig. 2c). When metal particles begin to oxidize, their edges preferentially nucleate to form a core-shell (metal-metal oxide) structure. The thin oxide shell acts as a template to support subsequent reactions.

(i) For continuous shells, due to the Kirkendall effect that diffusion coefficient of $\mathrm{Ni} / \mathrm{Co}$ is higher compared to oxygen, the central metal atoms can diffuse outward through the shell and are oxidized, generating a hollow particle with an expanding cavity [51-54]. Figure $2 d$ shows the TEM images of hollow oxide particles with different diameters of 17.80, 18.61, and $16.69 \mathrm{~nm}$. (ii) For shells with cracks, oxygen can enter the shell through the cracks, and the metal core is locally oxidized to form multiple cavities [54]. Figure 2e shows the presence of multiple-cavity in one oxide particle with the diameter ranging from 8.10 to $14.51 \mathrm{~nm}$. Furthermore, because of oxygen adsorptioninduced segregation effect, Co element is preferentially distributed on the outer edge of the shell rather than evenly distributed [55]. The TEM images in Fig. 2h show the

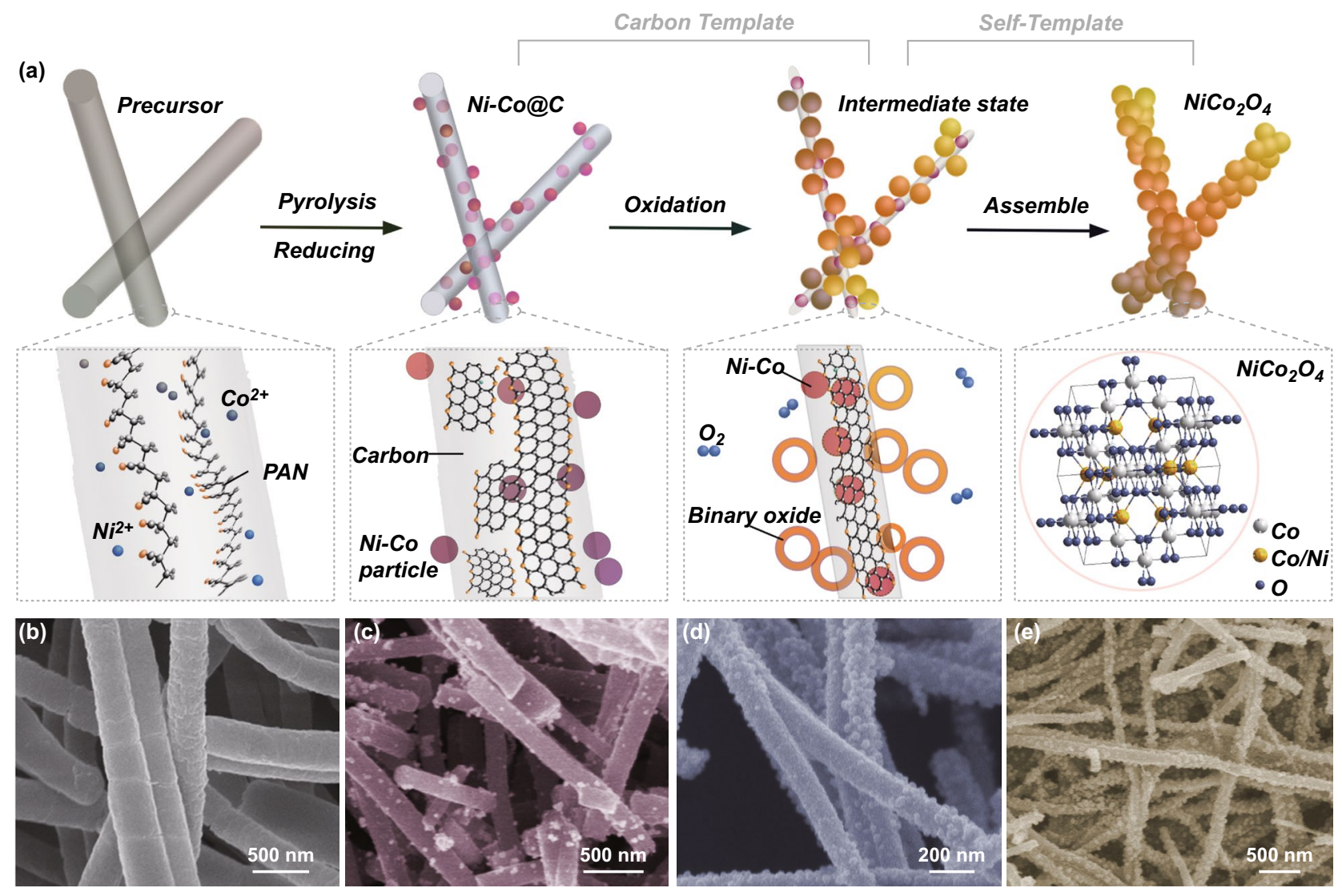

Fig. 1 a Growth process for $\mathrm{NiCo}_{2} \mathrm{O}_{4}$, and the corresponding cross-sectional view with different molecular structure. b-e SEM images corresponding to each growth process 
overall morphology of the nanofibers assembled by the hollow/multilocular bimetallic oxide nanoparticles. Such porous nanofibers are characterized by high specific surface and abundant electron transmission paths, leading to the improvement of materials' properties, especially the electrical property. Figure $2 \mathrm{i}$ shows that nanofibers are not smooth, and the interplanar spacings of the oxide nanoparticle are 0.468 and $0.286 \mathrm{~nm}$, respectively, indexed to the (111) and (220) planes of $\mathrm{NiCo}_{2} \mathrm{O}_{4}$. The corresponding analyses of XRD, Raman, and XPS spectra are shown in Fig. S1 [56-60].

\subsection{Electromagnetic Absorption Performance}

Since the fibrous morphology of N3 collapses (Fig. S2a-c), we only investigate the EM response of N1/N2. Figure 3a-c shows the EM responses of N1/N2-paraffin composites with loading content of 50, 70, and $90 \mathrm{wt} \%$. As the loading content of $\mathrm{NiCo}_{2} \mathrm{O}_{4}$ rises, $\varepsilon^{\prime}$ and $\varepsilon^{\prime \prime}$ increase. For each composite, $\varepsilon^{\prime}$ is trending downward due to the declined conductance and polarization response at high frequency. For characterizing the

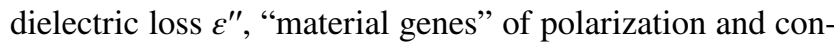
duction loss $\left(\varepsilon_{\mathrm{p}}{ }^{\prime \prime}\right.$ and $\left.\varepsilon_{\mathrm{c}}{ }^{\prime \prime}\right)$ are analyzed separately (Eqs. 1-3). $\varepsilon_{\mathrm{p}}{ }^{\prime \prime}$ is characterized by the relaxation peaks (I, II, and III). The multiple relaxation behaviors are arising from the inner friction of the dipole orientation polarization. $\varepsilon_{\mathrm{c}}$ " is characterized by the declining trend of $\varepsilon^{\prime \prime}$ due to the reduced conductance response. The relaxation peaks are becoming inconspicuous of 70/90 wt \% composites owing to the relatively improved $\sigma$ masking the peaks. Therefore, the synergy and competitive effect of polarization and conduction "genes" enable the modulation of the EM response. Figure $3 \mathrm{~d}-\mathrm{i}$ and $\mathrm{S} 3$ show that all composites possess dual absorption bands. The maximum $\mathrm{RL}$ reaches $-52.72 \mathrm{~dB}$ (70 wt\% N1). The ordinary RL of $70 / 90 \mathrm{wt} \% \mathrm{~N} 2(-15.13$ and $-10.50 \mathrm{~dB})$ originates from the growing reflection caused by the impedance mismatching between the material and free space.

Figure 4 shows the EM attenuation mechanism of the composite. When dispersed in paraffin matrix, the (a)
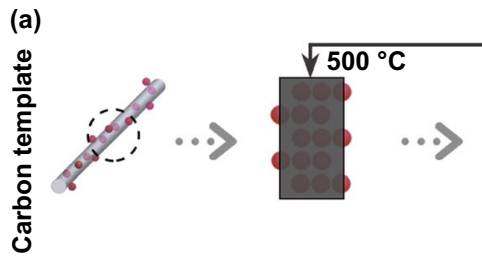

C nanofiber

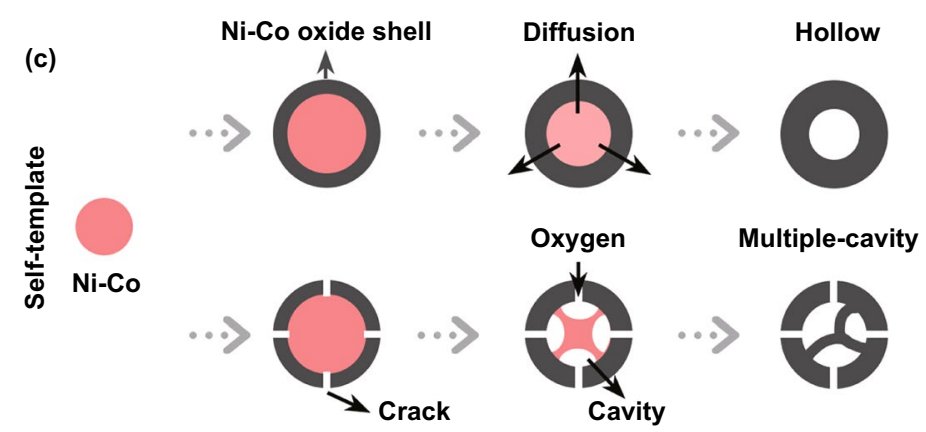

$\left(b_{1}\right)$

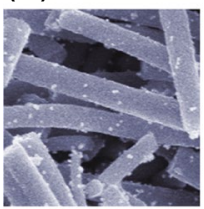

$\left(d_{1}\right)$

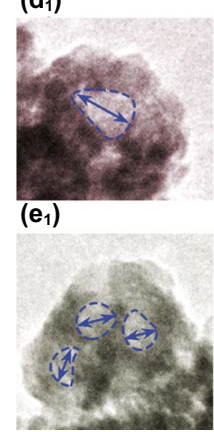

$\left(b_{2}\right)$

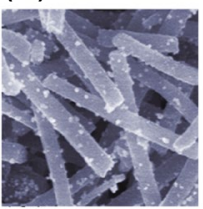

$\left(d_{2}\right)$

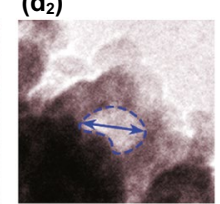

$\left(\mathbf{e}_{2}\right)$

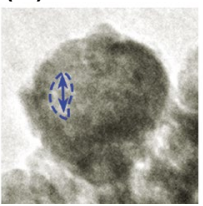

$\left(b_{3}\right)$

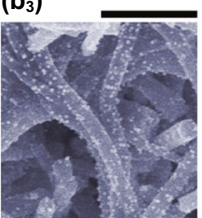

$\left(d_{3}\right)$
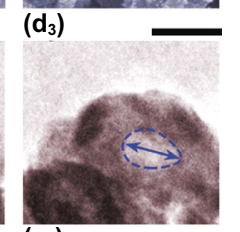

$\left(\mathbf{e}_{3}\right)$

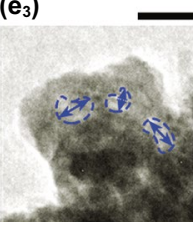

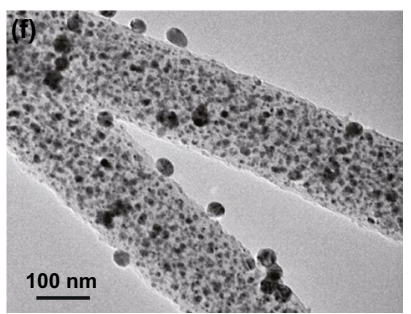
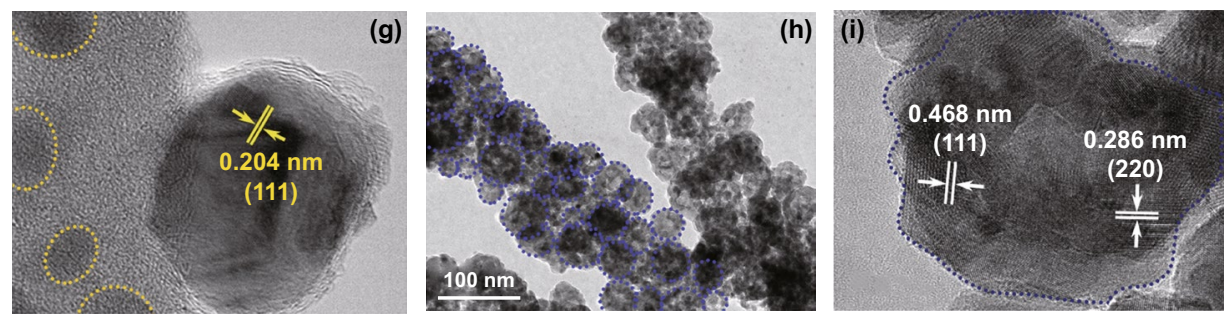

Fig. 2 a Effect of the calcination temperature on the C template. b Corresponding SEM images. Scale bar is 1 um. c Schematic of different oxidation processes affected by the continuity of the oxide shell. $\mathbf{d}$ Morphologies of hollow particles with different diameter. Scale bar is $20 \mathrm{~nm}$. $\mathbf{e}$ Morphologies of multiple-cavity particles. Scale bar is $20 \mathrm{~nm}$. $\mathbf{f}-\mathbf{g}$ TEM images of Ni-Co@C. h-i TEM images of $\mathrm{NiCo}_{2} \mathrm{O}_{4}$ 
one-dimensional $\mathrm{NiCo}_{2} \mathrm{O}_{4}$ and the rugged surface assembled by porous nanoparticles raise the probability of multiple reflections and scattering in the composite (Fig. 4a). In crystalline $\mathrm{NiCo}_{2} \mathrm{O}_{4}$, electrons absorb EM energy for transporting, including hopping the barrier and migrating in the network (Fig. 4b). The multi-cavity feature of $\mathrm{NiCo}_{2} \mathrm{O}_{4}$ nanoparticles not only reduces the density of the material, but also provides more channels for electron transmission, thus effectively improving the electron transmission efficiency. Figure $4 \mathrm{~d}$ shows the ratio of the contribution of $\varepsilon_{\mathrm{p}}{ }^{\prime \prime}$ and $\varepsilon_{\mathrm{c}}{ }^{\prime \prime}$ to the dielectric loss. It reveals that $\mathrm{NiCo}_{2} \mathrm{O}_{4}$ is a polarization-dominated EM absorbing material, since the preparation process will introduce abundant defects and groups to form dipoles (Fig. 4c). The cole-cole curves of $50 \mathrm{wt} \% \mathrm{~N} 1$ in Fig. 4e are derived from the polarization relaxation peaks at $2.4,4.2$, and $14.8 \mathrm{GHz}$. Figure $4 \mathrm{f}-\mathrm{h}$ shows three different types of dipoles, including asymmetric charge distribution on phase boundaries with different atomic arrangements, $\mathrm{Ni}$ atom vacancy $\left(V_{\mathrm{Ni}}\right)$, and oxygen vacancy $\left(V_{\mathrm{O}}\right)$. In addition, there are other relaxation derived from metal ions of (a)

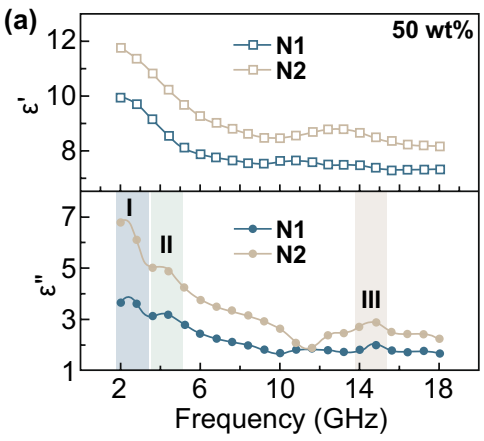

(d)
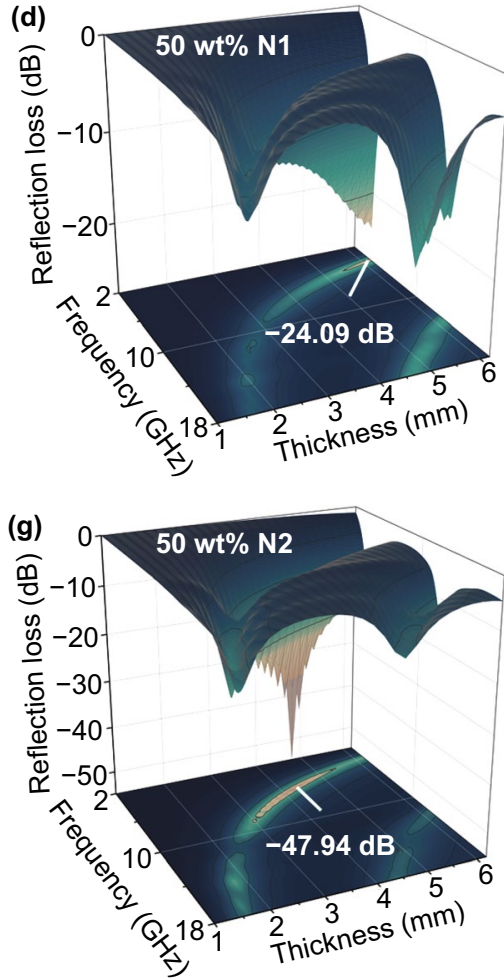

(b)

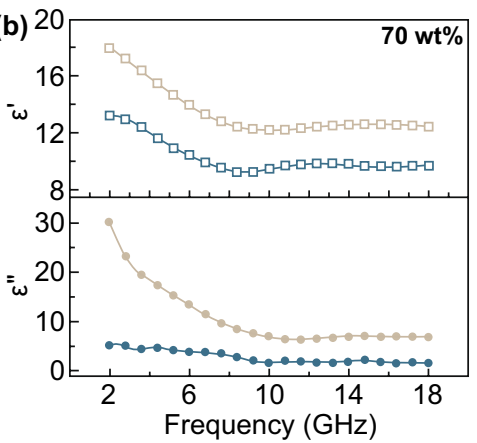

(e)

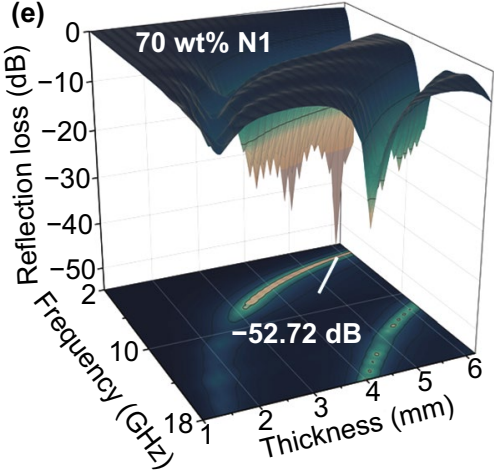

(h)

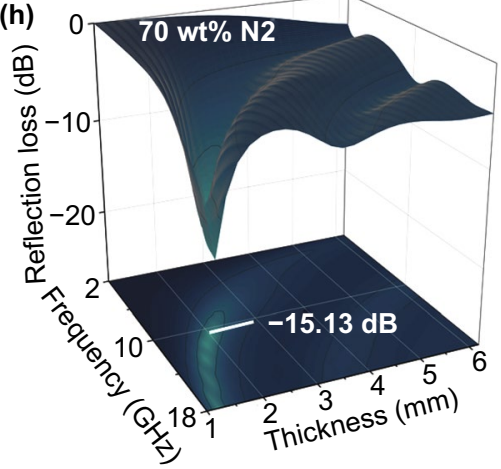

(c)

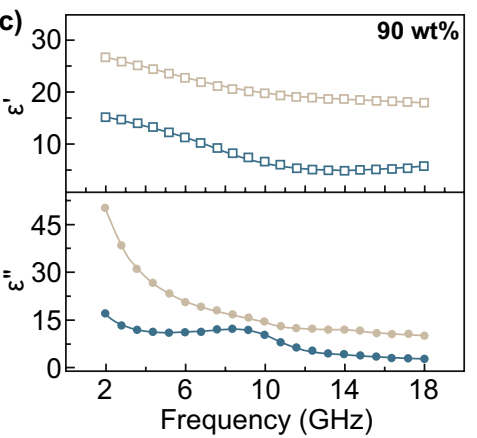

(f)
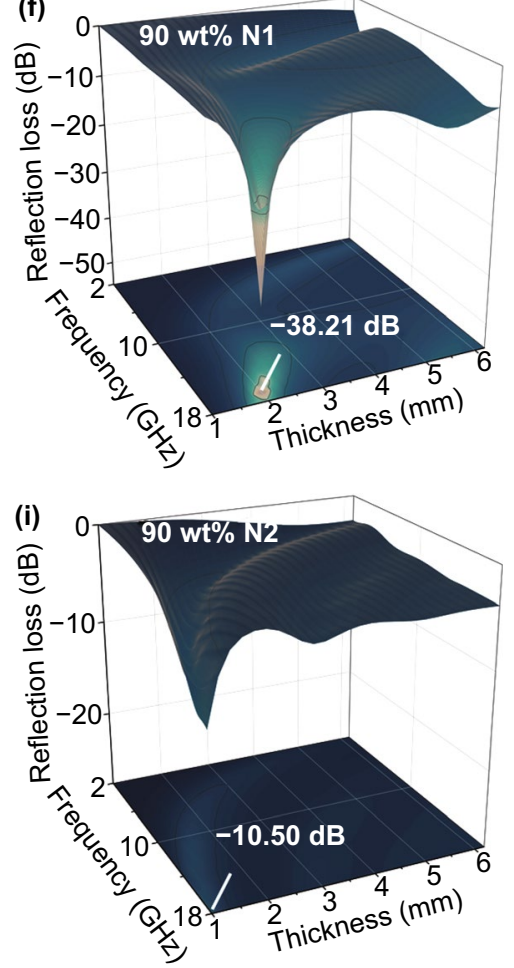

Fig. 3 a-c $\varepsilon^{\prime}$ and $\varepsilon^{\prime \prime}$ of $\mathrm{N} 1$ and $\mathrm{N} 2$ composites with different loading concentrations of $50 \mathrm{wt} \%, 70 \mathrm{wt} \%$, and $90 \mathrm{wt} \%$. d-f RL of N1 with different loading concentrations. $\mathbf{g}-\mathbf{i}$ RL of N2 with different loading concentrations 
different valence states $\left(\mathrm{Ni}^{2+/ 3+}, \mathrm{Co}^{2+/ 3+}\right)$ and impurity functional groups, which will attenuate EM energy by polarizing.

\subsection{Electromagnetic Interference Shielding Performance}

Generally, it is difficult for the EM absorption material to have the shielding performance, because the high $\sigma$ of the shielding material will lead to enhanced reflection and weakened absorption. However, by tailoring the porous nanofiber structure, $\mathrm{NiCo}_{2} \mathrm{O}_{4}$ possesses an extremely high effective absorption, enabling the EMI shielding function. The average EMI SE in 2-18 GHz for different samples with a thickness of $3 \mathrm{~mm}$ is shown in Fig. 5a (Fig. S4). $90 \mathrm{wt} \% \mathrm{~N} 2$ has the maximum value of $13.44 \mathrm{~dB}$. For all the samples, $\mathrm{SE}_{\mathrm{A}}$ dominates the SE. Its change (dotted lines) is consistent with the effective absorption efficiency $A_{\text {eff }}$ (Fig. 5b). $A_{\text {eff }}$ of $70 / 90 \mathrm{wt} \%$ N1/N2 exceeds $50 \%$, indicating that irrespective of reflection, EM wave is mostly used to support electron transport and establish polarization than transmission. When considering reflection, absorption coefficient $(A)$ of $90 \mathrm{wt} \%$ $\mathrm{N} 2$ slightly decreases, because its high $\sigma$ and strong reflection prevent some EM wave from entering the material. This is also why the samples of $90 \mathrm{wt} \% \mathrm{~N} 1$ and 70/90 wt\% N2 with excellent $A$ do not present high RL (Fig. 3). Samples are sorted based on $\sigma$ in Fig. 5c. At the same loading content, $\sigma$ of $\mathrm{N} 2$ is greater than N1. According to the aggregationinduced charge transport mode, the increase in $\sigma$ with the loading content results from the improvement of the conductive networks and the stacking/contacting sites for electron hopping. Therefore, raising $\sigma$ can improve $\varepsilon_{\mathrm{c}}{ }^{\prime \prime}$ so as to enhance $A_{\text {eff }}$ as well as RL, and conversely, raising $\sigma$ can strengthen reflection coefficient $(R)$ and $\mathrm{SE}_{\mathrm{R}}$ (Fig. 5d, and inset in Fig. 5c). Figure 5e shows the $\sigma$-driven EMI SE and RL has a competitive synergy. In region I, the increscent $\sigma$ has a positive effect on EM absorption. In region II, RL gradually declines, whereas the EMI SE gradually increases. This is due to that $\varepsilon_{\mathrm{c}}{ }^{\prime \prime}$ and $R$ will cause competition as $\sigma$ contributes to the both. In region III, reflection dominates and promotes the EMI SE, where $\sigma$ can be used as a switch to turn on the shielding performance. Here, EM absorbing and shielding of the $\mathrm{NiCo}_{2} \mathrm{O}_{4}$ composite exist simultaneously. In order to comprehensively evaluate the material's eco-friendliness, the green shielding index $\left(g_{\mathrm{s}}\right)$ is analyzed. According to $g_{s}=\frac{1}{\left|S_{11}^{2}\right|}-\frac{\left|S_{21}^{2}\right|}{\left|S_{11}^{2}\right|}-1$ (where $S_{11} / S_{21}$ represents the reflection/transmission coefficient), a high $g_{\mathrm{s}}$ suggests a small secondary reflection and a large effective absorption. When the value is greater than 1 , the secondary radiation (a)

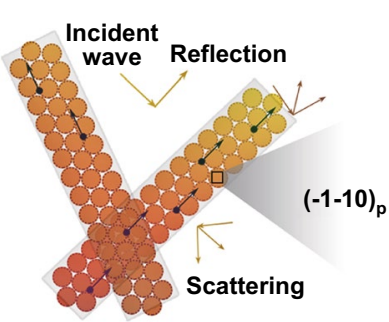

(e)

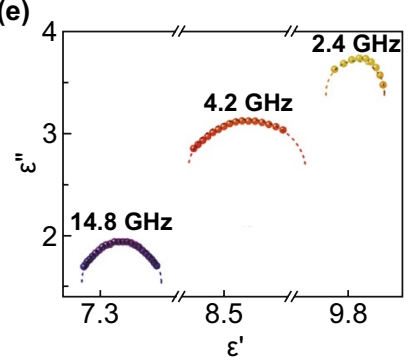

(b)

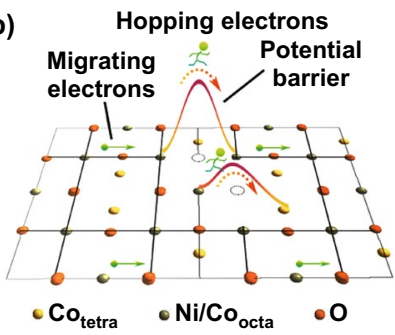

(f)

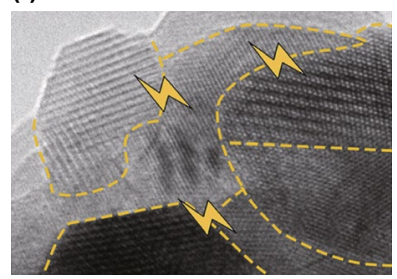

(c)

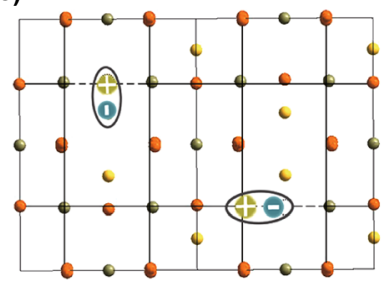

(g)

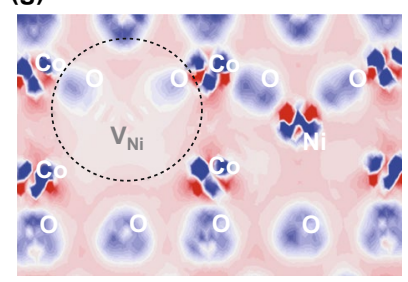

(d)

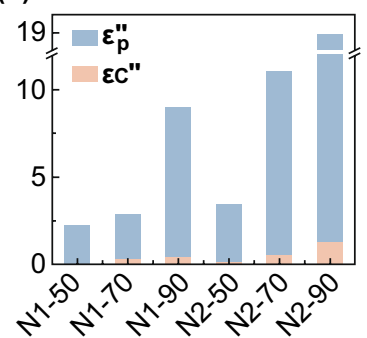

(h)

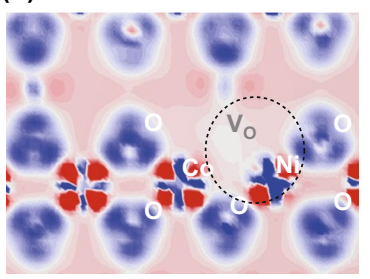

Fig. 4 EM attenuation mechanism of $\mathrm{NiCo}_{2} \mathrm{O}_{4}$ nanofibers. a Multiple reflection and scattering. b Conductive network and charge transport. c Polarization induced by defects. d The contribution of $\varepsilon_{\mathrm{p}}$ " and $\varepsilon_{\mathrm{c}}{ }^{\prime \prime}$ to $\varepsilon^{\prime \prime}$. The suffixes $-50,-70$, and -90 represent the loading concentration of the composites. e Cole-cole curves of $50 \mathrm{wt} \%$ N1. f Interfacial polarization observed from TEM image. $\mathbf{g}$, h Difference charge density around Ni vacancy $\left(V_{\mathrm{Ni}}\right)$ and oxygen vacancy $\left(V_{\mathrm{O}}\right)$ 
pollution is less compared with the effective absorption. In Fig. 5f, for all samples $g_{s} \geq 1$, implying shielding performance mainly depends on the inherent attenuation rather than reflection. Furthermore, it should be noted that the shielding performance has the potential for further optimization, if novel strategies for precisely tailoring materials are developed to enhance $A_{\text {eff }}$ and an optimal $\sigma$ that balances $\varepsilon_{\mathrm{c}}{ }^{\prime \prime}$ and $R$ is found. It is possible to achieve a prominent material with simultaneously high-efficiency EM absorbing and shielding, which is the challenge of the next work.

\subsection{Electromagnetic Sensor}

The excellent EM performance allows us to conceive new functional materials and EM-driven devices. By integrating the resonant coupling effect of patterned structure into the intrinsic EM properties of $\mathrm{NiCo}_{2} \mathrm{O}_{4}$ composite, a strain sensor is designed to wireless record of pressure (Fig. 6a and S5). The structure can be equivalent to an electrical circuit, containing the resistance $(\mathrm{R})$ of each component, the capacitance (C), and inductance (L) of zigzag pattern as well as the synergy of N1 and copper layers (Fig. 6b). The CST Microwave Studio for electric and magnetic field shows that the electric vectors resonate in the $x$-axis direction (Fig. 6c), while the magnetic vectors resonate in the $z$-axis direction (Fig. 6d). The corresponding energy density distributions demonstrate that electric component loss is concentrated in the patterned layer, and the magnetic component loss mainly occurs in the upper part due to the strong induced magnetic field by copper layer and N1 substrate. When the distance between the two N1 layers is compressed, the induced electric field caused by the magnetic vectors will overlap with the original electric vectors, thereby increasing the inductance coupling and modulating the response of reflection. Figure 6e shows the reflection spectra recorded from the structure. The resonance frequency shifts $\sim 1 \mathrm{GHz}$ by tuning the parameter $l$ from 0.4 to $1.4 \mathrm{~mm}$. Figure $6 \mathrm{f}$ shows that the resonance frequency is blue shifted and exhibits a linear response to $l$ due to the raised inductance coupling. To construct a strain sensing EM device, the space between the two N1 layers is filled with a silicon rubber. When the
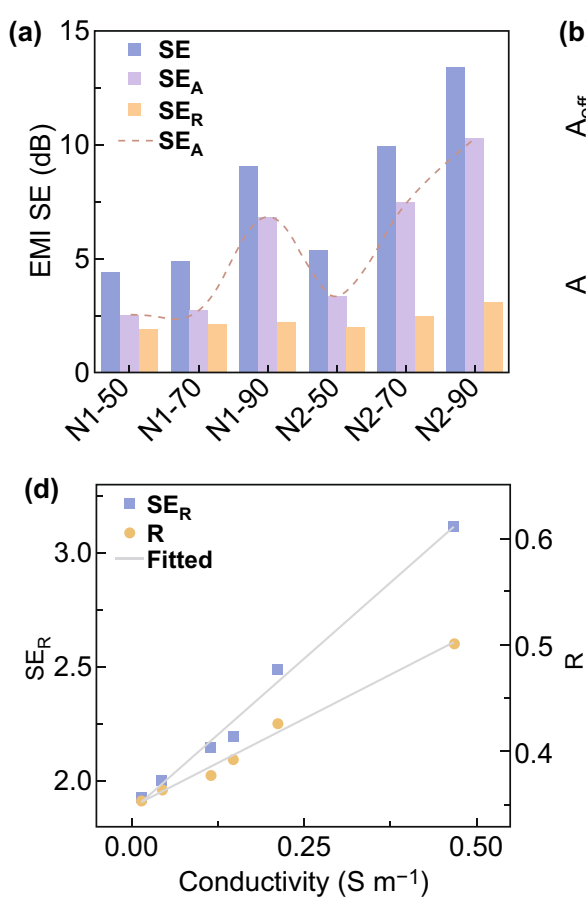

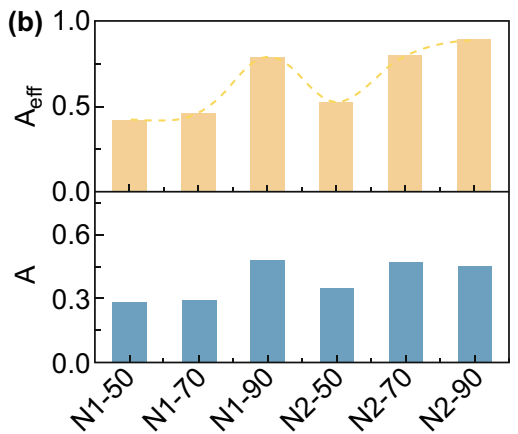

(e)

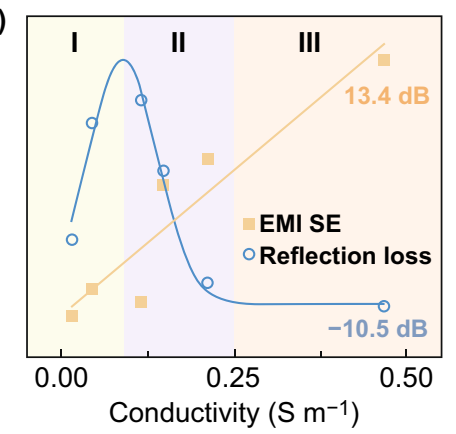

(c)
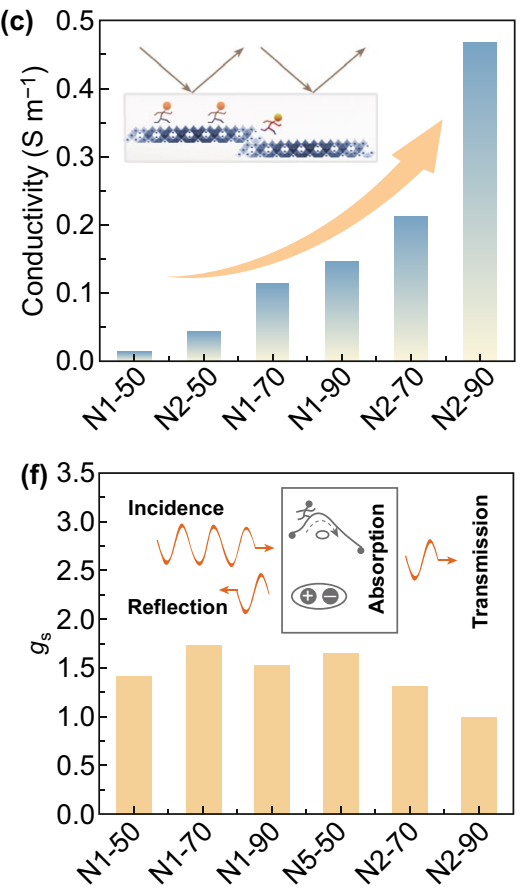

Fig. 5 a Average EMI SE, $\mathrm{SE}_{\mathrm{A}}$, and $\mathrm{SE}_{\mathrm{R}}$ of different $\mathrm{NiCo}_{2} \mathrm{O}_{4}$ composites. b Average effective absorption and absorption coefficient of different composites. $\mathbf{c} \sigma$ of the $\mathrm{NiCo}_{2} \mathrm{O}_{4}$ composites. Sort in ascending order. Inset: schematic of the effect of $\sigma$ on material properties. $\mathbf{d}$ SE $\mathrm{R}_{\mathrm{R}}$ and reflection coefficient versus $\sigma$. e Tendency of EM absorbing and shielding caused by charge transport. $\mathbf{f} g_{\mathrm{s}}$ of each sample. Inset, schematic of EM wave incidence, reflection, transmission, and absorption 
silicon rubber is compressed with strain, the increment of the resonance frequency ( $\Delta$ Frequency) is proportional to the strain $(S), \Delta f_{\mathrm{r}} \sim(0.012 \pm 5 \mathrm{E}-4) S$ (Fig. $\left.6 \mathrm{~g}\right)$. Compared to traditional sensors, this electromagnetic sensor with quick feedback shows greater competitiveness due to the ultrashort polarization establishment time of $\sim 10^{-9} \mathrm{~s}$. Thus, the strain sensor is a promising application in real-time and wireless pressure measurement for the $5 \mathrm{G}$ era.

\section{Conclusion}

In summary, a multifunctional $\mathrm{NiCo}_{2} \mathrm{O}_{4}$ nanofiber is successfully fabricated via dual-template method. By controlling the template state, EM response of $\mathrm{NiCo}_{2} \mathrm{O}_{4}$ can be tuned. In particular, the increased charge transport capacity not only plays a dominant role in $\varepsilon_{\mathrm{c}}$ " to promote EM attenuation, but reduces the degree of impedance matching, thus enhancing the EM reflection. Based on the results, the EM absorbing and green shielding functions of $\mathrm{NiCo}_{2} \mathrm{O}_{4}$ composite can be customized and coexistence. More importantly, a strain sensor device constructed by patterned $\mathrm{NiCo}_{2} \mathrm{O}_{4}$ composites is demonstrated. These findings open new horizons for design of multifunctional EM materials and will promote to expand the functions of $\mathrm{NiCo}_{2} \mathrm{O}_{4}$ to various fields, including metamaterials, sensing, and EM attenuation.

Acknowledgements This work was supported by National Natural Science Foundation of China (No. 51977009, 11774027, 51372282, and 51132002). The authors gratefully acknowledge Prof. Yuping Dong and Dr. Wenbo Dai for the photoluminescence and UV-Vis tests.

Open Access This article is licensed under a Creative Commons Attribution 4.0 International License, which permits use, sharing, adaptation, distribution and reproduction in any medium or format, as long as you give appropriate credit to the original author(s) and the source, provide a link to the Creative Commons licence, and indicate if changes were made. The images or other third party material in this article are included in the article's Creative Commons licence, unless indicated otherwise in a credit line to the
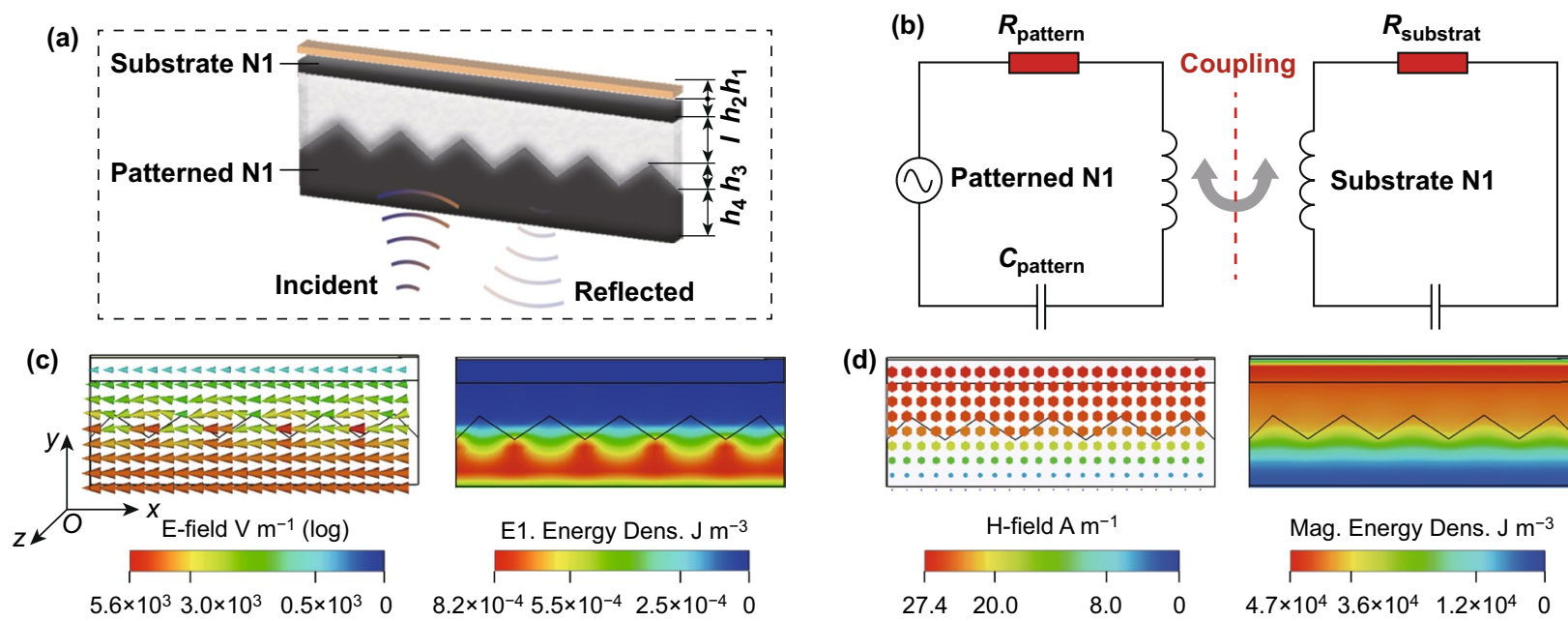

(d)
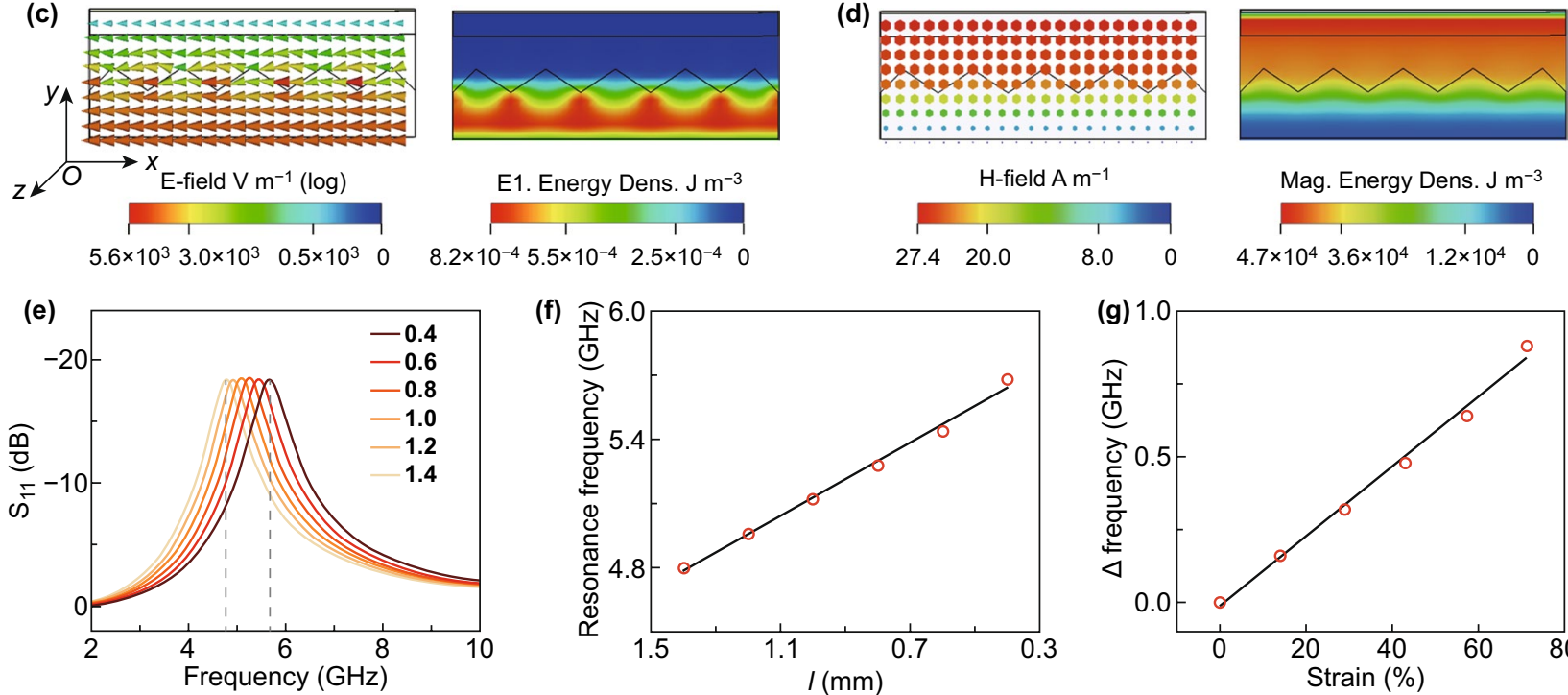

(f)
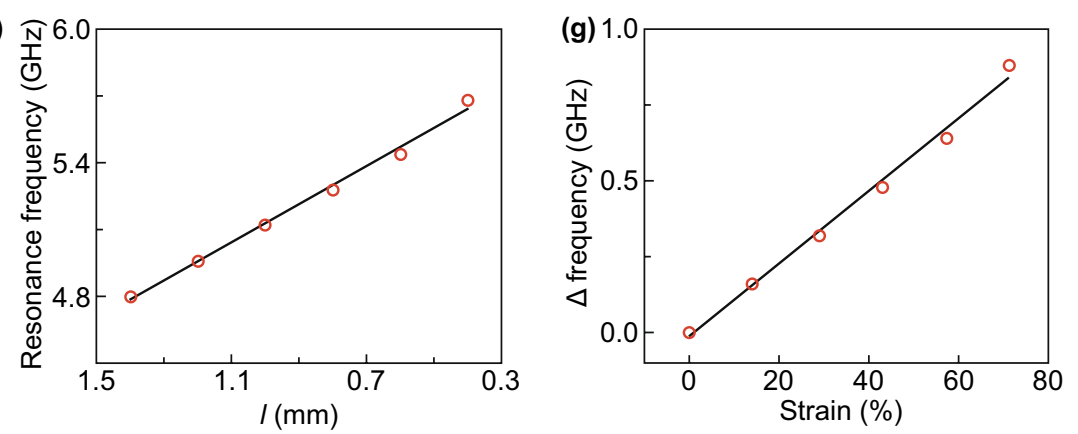

Fig. 6 a Schematic illustration for the sensor. b Equivalent circuit model of the device. c Simulated electric field, electric energy density distributions. d Simulated magnetic field, magnetic energy density distributions. e Reflection spectra vs. frequency at $l=0.4-1.4 \mathrm{~mm}$. f Distancesensitive resonance frequency response. $\mathrm{g}$ Strain-response curves 
material. If material is not included in the article's Creative Commons licence and your intended use is not permitted by statutory regulation or exceeds the permitted use, you will need to obtain permission directly from the copyright holder. To view a copy of this licence, visit http://creativecommons.org/licenses/by/4.0/.

Electronic supplementary material The online version of this article (https://doi.org/10.1007/s40820-020-00552-9) contains supplementary material, which is available to authorized users.

\section{References}

1. C. Chen, J.B. Xi, E.Z. Zhou, L. Peng, Z.C. Chen et al., Porous graphene microflowers for high-performance microwave absorption. Nano-Micro Lett. 10, 26 (2018). https://doi. org/10.1007/s40820-017-0179-8

2. X.H. Liang, Z.M. Man, B. Quan, J. Zheng, W.H. Gu et al., Environment-stable CoxNiy encapsulation in stacked porous carbon nanosheets for enhanced microwave. Nano-Micro Lett. 12, 102 (2020). https://doi.org/10.1007/s40820-020-00432-2

3. Y.Z. Li, Z.H. Liu, L. Li, W.H. Lian, Y.H. He et al., Tandemmass-tag based proteomic analysis facilitates analyzing critical factors of porous silicon nanoparticles in determining their biological responses under diseased condition. Adv. Sci. 7, 2001129 (2020). https://doi.org/10.1002/advs.202001129

4. V. Strauss, K. Marsh, M.D. Kowal, M. El-Kady, R.B. Kaner, A simple route to porous graphene from carbon nanodots for supercapacitor applications. Adv. Mater. 30, 1704449 (2018). https://doi.org/10.1002/adma.201704449

5. S.H. Liu, B. Shen, H.S. Hao, J.W. Zhai, Glass-ceramic dielectric materials with high energy density and ultra-fast discharge speed for high power energy storage applications. J. Mater. Chem. C 7, 15118-15135 (2019). https://doi.org/10.1039/ c9tc05253d

6. Y.L. Lian, B.H. Han, D.W. Liu, Y.H. Wang, H.H. Zhao et al., Solvent-free synthesis of ultrafine tungsten carbide nanoparticles-decorated carbon nanosheets for microwave absorption. Nano-Micro Lett. 12, 153 (2020). https://doi.org/10.1007/ s40820-020-00491-5

7. W.Y. Zhou, Y.J. Kou, M.X. Yuan, B. Li, H.W. Cai et al., Polymer composites filled with core@ double-shell structured fillers: effects of multiple shells on dielectric and thermal properties. Compos. Sci. Technol. 181, 107686 (2019). https://doi. org/10.1016/j,compscitech.2019.107686

8. Y. Zhang, C.H. Zhang, Y. Feng, T.D. Zhang, Q.G. Chen et al., Excellent energy storage performance and thermal property of polymer-based composite induced by multifunctional onedimensional nanofibers oriented in-plane direction. Nano Energy 56, 138-150 (2019). https://doi.org/10.1016/j.nanoe n.2018.11.044

9. C. Guan, X.M. Liu, W.N. Ren, X. Li, C.W. Cheng et al., Rational design of metal-organic framework derived hollow $\mathrm{NiCo}_{2} \mathrm{O}_{4}$ arrays for flexible supercapacitor and electrocatalysis. Adv. Energy Mater. 7, 1602391 (2017). https ://doi.org/10.1002/aenm.201602391

10. X.H. Hao, J.W. Zhai, L.B. Kong, Z.K. Xu, A comprehensive review on the progress of lead zirconate-based antiferroelectric materials. Prog. Mater Sci. 63, 1-57 (2014). https://doi. org/10.1016/j.pmatsci.2014.01.002

11. Z.H. Zeng, H. Jin, M.J. Chen, W.W. Li, L.C. Zhou et al., Lightweight and anisotropic porous MWCNT/WPU composites for ultrahigh performance electromagnetic interference shielding. Adv. Funct. Mater. 26, 303-310 (2016). https://doi. org/10.1002/adfm.201503579

12. D.Q. Zhang, T.T. Liu, J.Y. Cheng, Q. Cao, G.P. Zheng et al., Lightweight and high-performance microwave absorber based on $2 \mathrm{D} \mathrm{WS}_{2}$-RGO heterostructures. Nano-Micro Lett. 11, 38 (2019). https://doi.org/10.1007/s40820-019-0270-4

13. L. Wang, M.Q. Huang, X.F. Yu, W.B. You, J. Zhang et al., MOF-derived $\mathrm{Ni}_{1-\mathrm{x}} \mathrm{Co}_{\mathrm{x}} @$ carbon with tunable nano-microstructure as lightweight and highly efficient electromagnetic wave absorber. Nano-Micro Lett. 12, 150 (2020). https://doi. org/10.1007/s40820-020-00488-0

14. X.C. Zhang, J. Xu, H.R. Yuan, S. Zhang, Q.Y. Ouyang et al., Large-scale synthesis of three-dimensional reduced graphene oxide/nitrogen-doped carbon nanotube heteronanostructures as highly efficient electromagnetic wave absorbing materials. ACS Appl. Mater. Interfaces 11, 39100-39108 (2019). https ://doi.org/10.1021/acsami.9b13751

15. X. Li, W.B. You, L. Wang, J.W. Liu, Z.C. Wu et al., Selfassembly-magnetized MXene avoid dual-agglomeration with enhanced interfaces for strong microwave absorption through a tunable electromagnetic property. ACS Appl. Mater. Interfaces 11, 4454-44536 (2019). https://doi. org/10.1021/acsami.9b11861

16. F. Wu, M.X. Sun, C.C. Chen, T. Zhou, Y.L. Xia et al., Controllable coating of polypyrrole on silicon carbide nanowires as a core shell nanostructure: a facile method to enhance attenuation characteristics against electromagnetic radiation. ACS Sustain. Chem. Eng. 7, 2100-2106 (2019). https://doi. org/10.1021/acssuschemeng.8b04676

17. H.G. Wang, F.B. Meng, F. Huang, C.F. Jing, Y. Li et al., Interface modulating CNTs@PANi hybrids by controlled unzipping of the walls of CNTs to achieve tunable highperformance microwave absorption. ACS Appl. Mater. Interfaces 11, 12142-12153 (2019). https://doi.org/10.1021/ acsami.9b01122

18. O. Balci, E.O. Polat, N. Kakenov, C. Kocabas, Grapheneenabled electrically switchable radar-absorbing surfaces. Nat. Commun. 6, 6628 (2015). https://doi.org/10.1038/ncomm s10000

19. H.L. Lv, Z.H. Yang, P.L. Wang, G.B. Ji, J.Z. Song et al., A voltage-boosting strategy enabling a low-frequency, flexible electromagnetic wave absorption device. Adv. Mater. 30, 170634 (2018). https://doi.org/10.1002/adma.201706343

20. L. Wang, X.F. Yu, X. Li, J. Zhang, M. Wang et al., MOFderived yolk-shell Ni@C@ZnO Schottky contact structure for enhanced microwave absorption. Chem. Eng. J. 383, 123099 (2020). https://doi.org/10.1016/j.cej.2019.123099 
21. Y. Cheng, J.Z.Y. Seow, H.Q. Zhao, Z.C.J. Xu, G.B. Ji, A flexible and lightweight biomass-reinforced microwave absorber. Nano-Micro Lett. 12, 125 (2020). https://doi.org/10.1007/ s40820-020-00461-x

22. Y. Liu, Y.W. Fu, L. Liu, W. Li, J.G. Guan et al., Low-cost carbothermal reduction preparation of monodisperse $\mathrm{Fe}_{3} \mathrm{O}_{4} / \mathrm{C}$ core-shell nanosheets for improved microwave absorption. ACS Appl. Mater. Interfaces 10, 16511-16520 (2018). https ://doi.org/10.1021/acsami.8b02770

23. G.H. He, Y.P. Duan, H.F. Pang, Microwave absorption of crystalline Fe/MnO@C nanocapsules embedded in amorphous carbon. Nano-Micro Lett. 12, 57 (2020). https://doi. org/10.1007/s40820-020-0388-4

24. W. Li, T.L. Wu, W. Wang, P.C. Zhai, J.G. Guan, Broadband patterned magnetic microwave absorber. J. Appl. Phys. 116, 044110 (2014). https://doi.org/10.1063/1.4891475

25. N. He, Z.D. He, L. Liu, Y. Lu, F.Q. Wang et al., $\mathrm{Ni}^{2+}$ guided phase/structure evolution and ultra-wide bandwidth microwave absorption of $\mathrm{Co}_{\mathrm{x}} \mathrm{Ni}_{1-\mathrm{x}}$ alloy hollow microspheres. Chem. Eng. J. 381, 122743 (2020). https://doi.org/10.1016/j. cej.2019.122743

26. L.X. Huang, Y.P. Duan, X.H. Dai, Y.S. Zeng, G.J. Ma et al., Bioinspired metamaterials: multibands electromagnetic wave adaptability and hydrophobic characteristics. Small 15, 1902730 (2019). https://doi.org/10.1002/smll.201902730

27. K. Zhang, F. Wu, A.M. Xie, M.X. Sun, W. Dong, In situ stringing of metal organic frameworks by SiC nanowires for high-performance electromagnetic radiation elimination. ACS Appl. Mater. Interfaces 9, 33041-33048 (2017). https ://doi.org/10.1021/acsami.7b11592

28. J. Xu, X. Zhang, H.R. Yuan, S. Zhang, C.L. Zhu et al., $\mathrm{N}$-doped reduced graphene oxide aerogels containing podlike N-doped carbon nanotubes and FeNi nanoparticles for electromagnetic wave absorption. Carbon 159, 357-365 (2020). https://doi.org/10.1016/j.carbon.2019.12.020

29. P.B. Liu, S. Gao, Y. Wang, Y. Huang, W.J. He et al., Carbon nanocages with $\mathrm{N}$-doped carbon inner shell and $\mathrm{Co} / \mathrm{N}$ doped carbon outer shell as electromagnetic wave absorption materials. Chem. Eng. J. 381, 122653 (2020). https://doi. org/10.1016/j.cej.2019.122653

30. Q.H. Liu, Q. Cao, H. Bi, C.Y. Liang, K.P. Yuan et al., CoNi@SiO $\mathrm{SiO}_{2}$ and $\mathrm{ToNi} @ \mathrm{Air} @ \mathrm{TiO}_{2}$ microspheres with strong wideband microwave absorption. Adv. Mater. 28, 486 (2016). https://doi.org/10.1002/adma.201503149

31. P.B. Liu, Y.Q. Zhang, J. Yan, Y. Huang, L. Xia et al., Synthesis of lightweight $\mathrm{N}$-doped graphene foams with open reticular structure for high-efficiency electromagnetic wave absorption. Chem. Eng. J. 368, 285-298 (2019). https://doi. org/10.1016/j.cej.2019.02.193

32. M. Zhang, X.X. Wang, W.Q. Cao, J. Yuan, M.S. Cao, Electromagnetic functions of patterned $2 \mathrm{D}$ materials for micronano devices covering $\mathrm{GHz}, \mathrm{THz}$, and optical frequency. Adv. Opt. Mater. 7, 1900689 (2019). https://doi.org/10.1002/ adom.201900689

33. M. Green, A.T.V. Tran, X.B. Chen, Obtaining strong, broadband microwave absorption of polyaniline through data-driven materials discovery. Adv. Mater. Interfaces 7, 2000658 (2020). https://doi.org/10.1002/admi.202000658

34. M. Green, A.T.V. Tran, X.B. Chen, Maximizing the microwave absorption performance of polypyrrole by data-driven discovery. Compos. Sci. Technol. 199, 108332 (2020). https ://doi.org/10.1016/j.compscitech.2020.108332

35. M. Green, Y. Li, Z.H. Peng, X.B. Chen, Dielectric, magnetic, and microwave absorption properties of polyoxometalate-based materials. J. Magn. Magn. Mater. 497, 165974 (2020). https://doi.org/10.1016/j.jmmm.2019.165974

36. H.R. Lin, M. Green, L.J. Xu, X.B. Chen, B.W. Ma, Microwave absorption of organic metal halide nanotubes. Adv. Mater. Interfaces 7, 1901270 (2020). https://doi. org/10.1002/admi.201901270

37. M. Green, X.B. Chen, Recent progress of nanomaterials for microwave absorption. J. Materiomics 5, 503-541 (2019). https://doi.org/10.1016/j.jmat.2019.07.003

38. M. Green, Z.Q. Liu, P. Xiang, Y. Liu, M.J. Zhou, Doped, conductive $\mathrm{SiO}_{2}$ nanoparticles for large microwave absorption. Light-Sci. Appl. 7, 87 (2018). https://doi.org/10.1038/ s41377-018-0088-8

39. Z.P. Chen, C. Xu, C.Q. Ma, W.C. Ren, H.M. Cheng, Lightweight and flexible graphene foam composites for highperformance electromagnetic interference shielding. Adv. Mater. 25, 1296-1300 (2013). https://doi.org/10.1002/ adma.201204196

40. H.B. Zhang, Q. Yan, W.G. Zheng, Z.X. He, Z.Z. Yu, Tough graphene-polymer microcellular foams for electromagnetic interference shielding. ACS Appl. Mater. Interfaces 3, 918924 (2011). https://doi.org/10.1021/am200021v

41. H.L. Lv, Z.H. Yang, S.J.H. Ong, C. Wei, H.B. Liao et al., A flexible microwave shield with tunable frequency-transmission and electromagnetic compatibility. Adv. Funct. Mater. 29, 1900163 (2019). https://doi.org/10.1002/adfm.201900163

42. W.C. Jiang, F. Wu, Y.J. Jiang, M.X. Sun, K. Zhang et al., Synthesis of hollow $\mathrm{Cu}_{1.8} \mathrm{~S}$ nano-cubes for electromagnetic interference shielding. Nanoscale 9, 10961-10965 (2017). https:// doi.org/10.1039/c7nr02819a

43. Y. Li, X. Tian, S.P. Gao, L. Jing, K.R. Li et al., Reversible crumpling of 2D titanium carbide (MXene) nanocoatings for stretchable electromagnetic shielding and wearable wireless communication. Adv. Funct. Mater. 30, 1907451 (2020). https ://doi.org/10.1002/adfm.201907451

44. S. Lee, I. Jo, S. Kang, B. Jang, J. Moon et al., Smart contact lenses with graphene coating for electromagnetic interference shielding and dehydration protection. ACS Nano 11, 53185324 (2017). https://doi.org/10.1021/acsnano.7b00370

45. Q. Zhang, Q.J. Liang, Z. Zhang, Z. Kang, Q.L. Liao et al., Electromagnetic shielding hybrid nanogenerator for health monitoring and protection. Adv. Funct. Mater. 28, 1703801 (2018). https://doi.org/10.1002/adfm.201703801

46. X.X. Wang, J.C. Shu, W.Q. Cao, M. Zhang, J. Yuan et al., Eco-mimetic nanoarchitecture for green EMI shielding. Chem. Eng. J. 369, 1068-1077 (2019). https://doi.org/10.1016/j. cej.2019.03.164 
47. X.X. Wang, W.Q. Cao, M.S. Cao, J. Yuan, Assembling nano-microarchitecture for electromagnetic absorbers and smart devices. Adv. Mater. 32, 2002112 (2020). https://doi. org/10.1002/adma.202002112

48. S.K. Nataraj, K.S. Yang, T.M. Aminabhavi, Polyacrylonitrilebased nanofibers a state-of-the-art review. Prog. Polym. Sci. 37, 487-513 (2012). https://doi.org/10.1016/j.progpolyms ci.2011.07.001

49. M.S.A. Rahaman, A.F. Ismail, A. Mustafa, A review of heat treatment on polyacrylonitrile fiber. Polym. Degrad. Stabil. 92, 1421-1432 (2007). https://doi.org/10.1016/j.polymdegradstab .2007 .03 .023

50. K.L. Wu, X.W. Wei, X.M. Zhou, D.H. Wu, X.W. Liu et al., $\mathrm{NiCo}_{2}$ alloys: controllable synthesis, magnetic properties, and catalytic applications in reduction of 4-nitropheno. J. Phys. Chem. 115, 16268-16274 (2011). https://doi.org/10.1021/ jp201660w

51. Y. Yin, R.M. Rioux, C.K. Erdonmez, S. Hughes, G.A. Somorjai et al., Formation of hollow nanocrystals through the nanoscale Kirkendall effect. Science 304, 711-714 (2004). https://doi.org/10.1126/science.1096566

52. J.G. Railsback, A.C. Johnston-Peck, J. Wang, J.B. Tracy, Sizedependent nanoscale Kirkendall effect during the oxidation of nickel nanoparticles. ACS Nano 4, 1913-1920 (2010). https:// doi.org/10.1021/nn901736y

53. D.H. Ha, L.M. Moreau, S. Honrao, R.G. Hennig, R.D. Robinson, The oxidation of cobalt nanoparticles into kirkendallhollowed $\mathrm{CoO}$ and $\mathrm{Co}_{3} \mathrm{O}_{4}$ : the diffusion mechanisms and atomic structural transformations. J. Phys. Chem. C 117, 14303-14312 (2013). https://doi.org/10.1021/jp402939e
54. W.W. Xia, Y. Yang, Q.P. Meng, Z.P. Deng, M.X. Gong et al., Bimetallic nanoparticle oxidation in three dimensions by chemically sensitive electron tomography and in situ transmission electron microscopy. ACS Nano 12, 7866-7874 (2018). https://doi.org/10.1021/acsnano.8b02170

55. L.L. Han, Q.P. Meng, D.L. Wang, Y.M. Zhu, J. Wang et al., Interrogation of bimetallic particle oxidation in three dimensions at the nanoscale. Nat. Commun. 7, 13335 (2016). https ://doi.org/10.1038/ncomms13335

56. A.C. Ferrari, J. Robertson, Interpretation of Raman spectra of disordered and amorphous carbon. Phys. Rev. B 61, 1409514107 (2000). https://doi.org/10.1103/PhysRevB.61.14095

57. L.G. Cancado, A. Jorio, E.H.M. Ferreira, F. Stavale, C.A. Achete et al., Quantifying defects in graphene via raman spectroscopy at different excitation energies. Nano Lett. 11, 3190-3196 (2011). https://doi.org/10.1021/nl201432g

58. M.N. Iliev, D. Mazumdar, J.X. Ma, A. Gupta, F. Rigato et al., Monitoring B-site ordering and strain relaxation in $\mathrm{NiFe}_{2} \mathrm{O}_{4}$ epitaxial films by polarized Raman spectroscopy. Phys. Rev. B 83, 014108 (2011). https://doi.org/10.1103/PhysR evB.83.014108

59. V.G. Ivanov, M.V. Abrashev, M.N. Iliev, M.M. Gospodinov, J. Meen et al., Short-range B-site ordering in the inverse spinel ferrite $\mathrm{NiFe}_{2} \mathrm{O}_{4}$. Phys. Rev. B 82, 024104 (2010). https://doi. org/10.1103/PhysRevB.82.024104

60. J.C. Dupin, D. Gonbeau, P. Vinatier, A. Levasseur, Systematic XPS studies of metal oxides, hydroxides and peroxides. Phys. Chem. Chem. Phys. 2, 1319-1324 (2000). https://doi. org/10.1039/a908800h 